\title{
Bond of steel reinforcement with microwave cured concrete repair mortars
}

\author{
P. S. Mangat $\cdot$ Shahriar Abubakri $\cdot$ Konstantinos Grigoriadis
}

Received: 30 June 2017 / Accepted: 17 November 2017 / Published online: 28 November 2017

(C) The Author(s) 2017. This article is an open access publication

\begin{abstract}
This paper investigates the effect of microwave curing on the bond strength of steel reinforcement in concrete repair. Pull-out tests on plain mild steel reinforcement bars embedded in four repair materials in $100 \mathrm{~mm}$ cube specimens were performed to determine the interfacial bond strength. The porosity and pore structure of the matrix at the steel interface, which influence the bond strength, were also determined. Test results show that microwave curing significantly reduces the bond strength of plain steel reinforcement. The reduction relative to normally cured $\left(20{ }^{\circ} \mathrm{C}, 60 \% \mathrm{RH}\right)$ specimens is between 21 and $40 \%$ with low density repair materials and about $10 \%$ for normal density cementitious mortars. The corresponding compressive strength of the matrix also recorded similar reduction and microwave curing resulted in increased porosity at the interface transition zone of the steel reinforcement.
\end{abstract}

P. S. Mangat $(\varangle) \cdot$ S. Abubakri

Centre for Infrastructure Management, Materials and Engineering Research Institute, Sheffield Hallam University, Howard Street, Sheffield S1 1WB, UK e-mail: p.s.mangat@shu.ac.uk

S. Abubakri

e-mail: s.abubakri@shu.ac.uk

K. Grigoriadis

School of Natural and Built Environment, Queens University, David Keir Building, Stranmillis Road, Belfast, Northern Ireland BT9 6AX, UK

e-mail: k.grigoriadis@qub.ac.uk
A unique relationship exists between bond strength and both compressive strength and porosity of all matrix materials. Microwave curing reduced shrinkage but despite the wide variation in the shrinkage of the repair mortars, its effect on the bond strength was small. The paper provides clear correlations between the three parameters (compressive strength, bond strength and porosity), which are common to both the microwave and conventionally cured mortars. Therefore, bond-compressive strength relationships used in the design of reinforced concrete structures will be also valid for microwave cured elements.

Keywords Microwave curing - Bond strength · Shrinkage $\cdot$ Porosity $\cdot$ Compressive strength $\cdot$ Concrete repair

$\begin{array}{ll}\begin{array}{ll}\text { Abbreviations } \\ d\end{array} & \begin{array}{l}\text { Diameter of mild steel bar (mm) } \\ l\end{array} \\ & \begin{array}{l}\text { Length of the steel bar in contact with the } \\ \text { repair (mm) }\end{array} \\ F & \text { Applied force }(\mathrm{KN}) \\ f_{\mathrm{b}} & \text { Bond strength }(\mathrm{MPa}) \\ f_{\mathrm{c}} & \text { Compressive Strength }(\mathrm{MPa}) \\ \mathrm{SD} & \text { Standard deviation } \\ \mathrm{MIP} & \text { Mercury Intrusion Porosimetry } \\ v_{\mathrm{p}} & \text { Loading rate of pull-out test }(\mathrm{N} / \mathrm{s}) \\ \tau & \text { Bond stress }(\mathrm{MPa}) \\ r & \text { Radius of pore }(\mathrm{nm}) \\ P & \text { Applied pressure }(\mathrm{Pa})\end{array}$


$p \quad$ Porosity

$\gamma \quad$ Surface tension of mercury $((\mathrm{N} / \mathrm{m})$

$\theta \quad$ Contact angle between mercury and concrete $\left({ }^{\circ}\right)$

\section{Introduction}

Reinforced and pre-stressed concrete infrastructure in the world has approached a stage where repair is often necessary due to various concrete degradation mechanisms, abnormal loading or poor workmanship. Although most concrete construction is highly durable in all kinds of environments, the concrete repair and maintenance market has grown exponentially in recent decades due to significant durability failures. It is essential to regularly monitor the performance of reinforced concrete infrastructure and carry out timely repair to extend the service life of the concrete structures and to prevent failure. However, factors affecting the durability of repair itself have become a concern in recent years as most repairs prove unsatisfactory within a few years $[1,2]$.

The rapid development of strength at early age during the application of repair is highly desirable as it can provide an efficient and economic repair. This enables minimum disruption to traffic, for example, during localised repair in concrete pavements. Precast industry can also benefit from rapid strength development by increasing their turnover. Another important economic advantage provided by high early age strength development is to enable concrete construction in cold weather [3]. This will allow continuous construction activity in winter, thereby improving the economics of the construction industry in cold regions of the world.

Conventional heating methods are currently used in the concrete industry to achieve high early-age compressive strength of concrete. However, there are limitations with these methods [4] and they cannot be used efficiently, safely and economically especially for in situ repair or for new construction on site. Microwave technology, on the other hand, is potentially a very effective method to cure cementitious repair materials at early age and develop strength rapidly. Unlike conventional heating, microwave curing generates heat from within concrete or a repair patch to provide uniform heating across its depth. Less than $1 \mathrm{~h}$ of microwave exposure applied in the first stage of hydration is sufficient to achieve the desired curing temperature [5-7]. There is already considerable research [8-12] on the use of early age microwave curing to accelerate strength development of concrete. The expected advantages of microwave curing have led to research around the world on developing microwave prototype systems [13-15] for commercial use.

Most of the research on microwave curing of concrete has focused on normal concrete materials with limited attention to steel reinforced concrete and to in situ concrete repair which incorporates both proprietary repair mortars and steel reinforcement. Microwave curing of concrete with steel reinforcement raises two basic concerns. The first is safety relating to the electrically charged or reflected microwave energy causing sparks and overheating at the steel surface. The second concern is the effect of microwave curing on the bond between steel reinforcement and concrete, which is fundamental to the composite action of reinforced concrete. The first concern has been addressed by exposing parts of steel reinforcement protruding from concrete specimens to microwave powers of up to $420 \mathrm{~W}$ without recording any adverse effect [5]. The second aspect of reinforcement bond strength is addressed in this paper. It deals with the bond of plain steel reinforcement embedded in different concrete repair materials. Another aspect of bond strength which is of critical importance for the efficient performance of concrete repair is the interfacial bond between the substrate concrete and patch repair, which has been reported elsewhere [16].

The composite performance of reinforced concrete depends on the efficient interaction between the steel reinforcement and the concrete matrix, which relies on their bond strength. Plain steel bars provide a true bond failure mechanism with concrete, which includes chemical adhesion and frictional resistance. The pull out strength of deformed reinforcement bars overestimates the basic bond strength by including the mechanical interlock strength of the concrete [17]. The simple pull-out mechanism of the plain rebar embedded in concrete is made more complex by the bursting forces generated by the wedge action of ribs on the rebar which is confined to different degrees by the concrete cover and confining reinforcement 
$[18,19]$. The bond behaviour is influenced by factors such as the rib geometry, their relative surface area [20] and interlock with concrete lugs [21]. The fib model design code [22] provides a basic expression for rebar bond strength, relating it to the square root of concrete strength while also incorporating other empirical coefficients which depend on many parameters such as geometry of the section, strength, diameter and surface geometry of reinforcement, concrete cover, bar spacing and confinement of reinforcement [22]. However, the main aim of the research reported in this paper is to isolate and determine the effect of microwave curing on reinforcement bond strength without introducing other factors which may interfere with the clarity of results. Therefore, plain reinforcement bars have been used in the experimental programme to provide a basic bond mechanism. In practice also, many reinforced concrete structures which have been constructed with plain steel bars in the past have reached their repair stage and the bond of this reinforcement in repair patches has become important.

The main parameters of microwave curing which are likely to affect the interfacial bond strength are the porosity and pore structure of the matrix at the steel interface, the shrinkage of the matrix and its compressive strength. Therefore, in addition to pull out tests of reinforcement, the test programme of this investigation also determines the effect of microwave curing on the porosity and pore structure of the matrix by mercury intrusion porosimetry, shrinkage and compressive strength by standard test methods [23]. The results of the bond strength are related to these parameters.

This paper is part of a larger research project funded by the European Commission on microwave curing of patch repair and to develop a prototype system for in situ curing of concrete patch repairs (FP7 MCure project). The prototype has been successfully tested on $1 \mathrm{~m} \times 1 \mathrm{~m}$ patch repairs and is being taken to the next stage of commercial development.

\section{Test programme}

\subsection{Materials}

The following commercial repair materials were used in this investigation:
Repair Material 1 A proprietary shrinkage-compensated, rapid hardening cement mortar with pulverised fuel ash. Density of the fresh mix was $2260 \mathrm{~kg} /$ $\mathrm{m}^{3}$.

Repair Material 2 A proprietary polymer-modified cement mortar, fibre-reinforced and shrinkage-compensated. Density of the fresh mix was $1730 \mathrm{~kg} / \mathrm{m}^{3}$.

Repair Material 3 A proprietary lightweight, low permeability, polymer-modified cement mortar. Density of the fresh mix was $1540 \mathrm{~kg} / \mathrm{m}^{3}$.

Repair Material 4 A mortar with CEM II/A-L 32.5 R Portland-limestone cement [24], coarse sharp sand (50\% passing a $600 \mu \mathrm{m}$ sieve) and $\mathrm{w} / \mathrm{c}$ ratio of 0.45 . Density of fresh mix was $2200 \mathrm{~kg} / \mathrm{m}^{3}$.

\subsection{Microwave curing regime}

A Sharp Model R-2370 commercial microwave oven with a maximum actual output power of $1320 \mathrm{~W}$ was used for curing the specimens. It was calibrated according to ASTM F1317 [25] and BS EN 60705 [26]. The microwave oven could be set to generate power at incremental levels of $10 \%$ up to $100 \%$ of its maximum output. The microwave frequency of the oven was $2.45 \mathrm{GHz}$. A $10 \%$ power level was used to generate actual output power of $132 \mathrm{~W}$ to microwave cure specimens. Lower powers of 92 and $60 \mathrm{~W}$ were also used for some tests.

\subsection{Details of specimens, casting, curing and testing}

\subsubsection{Details of specimens}

The effect of microwave curing on the bond strength between plain (un-deformed) mild steel bars and various repair materials was determined in a laboratory investigation. Steel bars of diameter $10 \mathrm{~mm}$ and length $255 \mathrm{~mm}$ were used in the investigation. One end of each steel bar was machined on a lathe to create a threaded length up to $15 \mathrm{~mm}$ to connect the test specimen to a hinge joint which provided alignment of the specimen with the applied load during the pull out test. Prior to casting the specimens, each steel bar was cleaned with acetone and dried before it was placed horizontally across the entire length of a $100 \mathrm{~mm}$ polystyrene cube mould (wall thickness of $20 \mathrm{~mm}$ ) by drilling two opposite vertical faces of the mould. The bar was located along the central axis of the cube and 
its threaded and un-threaded ends extended 85 and $30 \mathrm{~mm}$ respectively beyond the two opposite faces of the polystyrene mould. A plastic sleeve was inserted on the steel bar to provide a $50 \mathrm{~mm}$ unbonded length within the cube (Fig. 1). Hence, the effective bond length between the steel bar and the repair material was $50 \mathrm{~mm}$.

For each repair material, 12 pull-out specimens were cast from three mixes. Half of the specimens were cured normally $\left(20^{\circ} \mathrm{C}, 60 \% \mathrm{RH}\right)$ and the other half were microwave cured. An additional 4 specimens ( 2 normally and 2 microwave cured) were cast in a similar way to the pull-out test specimens, which were used to investigate the effect of microwave curing on the porosity of the interfacial transition zone (ITZ)

The effect of microwave curing on compressive strength was investigated by casting four $75 \times 75 \times 75 \mathrm{~mm}$ cube specimens in polystyrene moulds. Two specimens were normally cured and the other two were microwave cured. Four shrinkage prism specimens of dimensions $75 \times 75 \times 300 \mathrm{~mm}$ were cast in polystyrene moulds. Two specimens were normally cured and the other two by microwave.

\subsubsection{Casting and curing}

A quantity of repair mortar powder and water was mixed together in a Hobart mortar mixer. Each mix was cast in the polystyrene moulds and compacted on

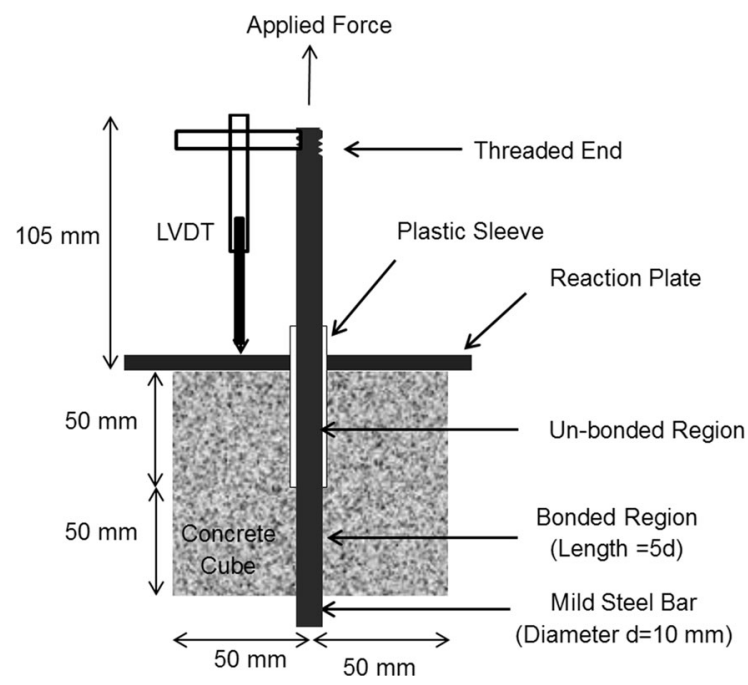

Fig. 1 Schematic diagram of pull-out test a vibrating table. The compacted specimens were kept in the laboratory environment (approximately $20{ }^{\circ} \mathrm{C}$, $60 \% \mathrm{RH}$ ) for $30 \mathrm{~min}$ from the time of commencing mixing and then half of the specimens were placed in the microwave oven and cured to reach approximately $40-45{ }^{\circ} \mathrm{C}$ as determined by Mangat et al. [5]. The pullout cube specimens (Fig. 1) made with four different repair materials were subjected to microwave curing using powers of 132 (Series 1), 92 (Series 2) and 60 (Series 3) Watts (Table 1). The temperature was measured at the centre of the top surface of each specimen at the start of microwave curing and then after every $10 \mathrm{~min}$ until the end of microwave curing using a Flir i7 thermal camera. The specimens were removed briefly from the microwave cavity to measure temperature at each time increment and then placed back for further microwave curing. The duration of microwave curing was 20-44 min for different materials and applied powers (W) to achieve similar maximum top surface temperatures of $40-45{ }^{\circ} \mathrm{C}$ (Table 1). The ends of the steel bars protruding from the polystyrene mould of each repair were directly exposed to the microwaves during the curing period. The cube, prism, and MIP specimens described in Sect. 2.3.1 were cured in the same manner as described above.

Three phases of cement hydration processes are considered for starting microwave curing based on the relationship between the dielectric properties of microwaves and the heat generation and transfer properties of microwave energy [5, 6]. These are the early dormant period (during setting), the middle period (at the end of setting) and the final period (during strength development with continuing hydration). The early dormant period (phase 1) is suitable for microwave curing when the system contains both water molecules and cement which continue to react with each other [5, 6]. This period of curing also provides the best compromise between the rate of strength gain and the long term strength of concrete, which has to be made in most practical applications. Application of microwave curing during the middle and final phases, on the other hand, will be more disruptive to the internal structures formed by hydration and result in greater reduction in long term strength $[5,7]$.

The optimum time between the start of mixing and application of microwave curing (delay time) for developing very high early strength concrete was 
Table 1 Details of bond strength tests

\begin{tabular}{lllll}
\cline { 2 - 5 } & 1 & 1 & 132 & 30 \\
& 2 & & 20 \\
& 3 & & 30 \\
*Only for pull out test & $2 *$ & 3 & 92 & 30 \\
specimens & $3 *$ & 3 & 60 & 44 \\
\cline { 2 - 6 }
\end{tabular}

found to be $30 \mathrm{~min}$, within the investigated range of 20-61 min [9]. Similarly the results of Makul and Agrawal [11] produced optimum compressive strength with a delay time of $30 \mathrm{~min}$. A $30 \mathrm{~min}$ delay time was also used by Sohn and Johnson [10], investigating the effect of microwave curing on the 28 day strength where the optimum curing temperature was found to be $40{ }^{\circ} \mathrm{C}$ for cement and $60{ }^{\circ} \mathrm{C}$ for blended mortars.

Immediately after microwave curing, the samples were covered with plastic sheets and stored in the laboratory (at $20{ }^{\circ} \mathrm{C}, 60 \% \mathrm{RH}$ ) together with the normally cured control samples which had remained there since casting. All specimens (normally and microwave cured) were de-moulded $24 \mathrm{~h}$ after casting and cured in the laboratory air (approximately $20{ }^{\circ} \mathrm{C}$, $60 \% \mathrm{RH})$ until testing at 42 days age.

\subsubsection{Testing}

Bond strength was determined at 42 days age by the pull-out test according to BS EN 10080 [27], as shown in Fig. 1. Assuming a uniform bond stress distribution over the effective embedded length in the repair material, the average bond stress which is related to the pull-out tension force is calculated by the following formula:

$\tau=\frac{F}{\pi d l}$

where $\tau$ is the average bond stress (MPa); $F$ is the maximum pull-out tensile force $(N)$; $d$ is the diameter $(10 \mathrm{~mm})$ and $l$ is the embedded length of the steel bar (50 mm, Fig. 1).

The loading rate was determined according to BS EN 10080 [27], by the following formula:

$v_{p}=0.56 d^{2}$ where $v_{p}$ is the loading rate $(\mathrm{N} / \mathrm{s})$ and $d$ is the diameter of the steel bar (mm).

The pull-out specimens were tested in a computer controlled ESH Four Column Universal testing machine with maximum capacity of $250 \mathrm{KN}$. The tensile force was applied to the longer (threaded) end of the steel bar connected through a hinge to the jaws of the machine. A loading rate of $55 \mathrm{~N} / \mathrm{s}$ was used. The load and slip, at the loaded end of the bar, were automatically recorded by the machine computer. No yielding of the steel bar was observed in any of the tests. The elongation of the un-bonded steel bar from the loaded end point, during the test, was negligible relative to the slip.

The effect of microwave curing on the porosity and pore size distribution was determined by mercury intrusion porosimetry using the PASCAL 140/240 Porosimeter. The $100 \mathrm{~mm}$ cube "pull-out" specimens were subjected to the tensile split test to split them at the middle along the steel bar. Then mortar samples with a weight of 1-2 $g$ were collected for MIP testing near the middle of the bond specimens (representing the bulk mortar of all materials) and also from the interface with the steel bar (for Materials 2 and 3). The specimens were prepared for MIP testing by placing them inside an oven at $60{ }^{\circ} \mathrm{C}$ for 3 days. Then, they were immersed in acetone for $4 \mathrm{~h}$ before placing them inside a desiccator for a minimum of $24 \mathrm{~h}$ until they were tested. The diameter of pores was calculated according to the Washburn equation given below:

$r=\frac{-4 \gamma \cos \theta}{P}$

where $P$ is the applied pressure $(\mathrm{Pa}) ; r$ is the radius of pores $(\mathrm{nm}) ; \gamma$ is the surface tension of mercury $\left(\mathrm{N} \mathrm{m}^{-1}\right) ; \theta$ is the contact angle between mercury and concrete (assumed as $140^{\circ}$ ). The surface tension of mercury is $0.48 \mathrm{~N} \mathrm{~m}^{-1}$. 
Compressive strength was determined by testing two cube specimens $(75 \mathrm{~mm})$ for each material and curing condition according to the BS 12390-3:2009 [23] at 42 days age. Drying shrinkage was determined by recording length change of the two prisms per curing condition (microwave and normally cured) of each repair material up to 42 days age. The $75 \times 75 \times 300 \mathrm{~mm}$ prism specimens were demoulded and demec points were attached at the two opposite side faces to monitor shrinkage strain. The first (datum) demec reading was taken at $24 \mathrm{~h}$ age from commencing mixing. Subsequent readings were taken at regular intervals.

\section{Results and discussion}

\subsection{Microwave curing temperature}

Temperature of microwave curing is one of the most important parameters that affects the properties of repair. The target curing temperature of approximately $40-45^{\circ} \mathrm{C}$ was used in this investigation as recommended by Mangat et al. [5]. This target temperature takes into account factors such as temperature variation under microwave exposure, heat of hydration and the effect of high temperature curing on durability [5].

Figure 2 shows typical Time-Temperature graphs, recorded during microwave curing at $132 \mathrm{~W}$, of two pull-out bond specimens. The ambient temperature was approximately $20{ }^{\circ} \mathrm{C}$. The temperature increased linearly during microwave curing. Temperature variation between the two specimens in Fig. 2 is $8 \%$ which

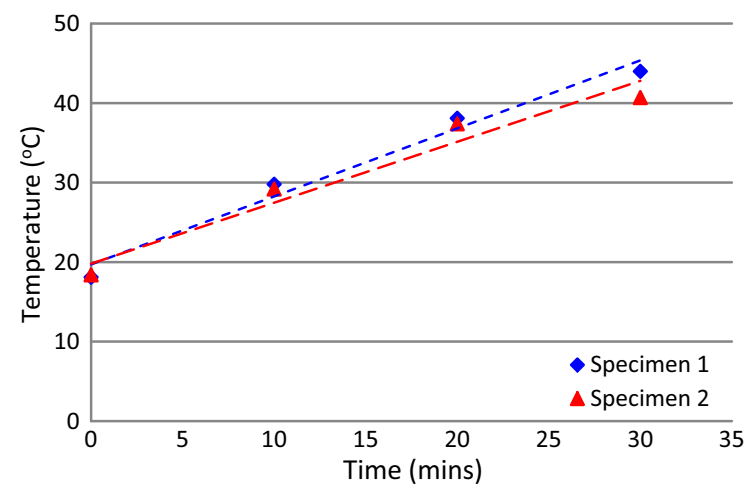

Fig. 2 Typical temperature profiles for microwave cured Material 1 is due to the different location of each specimen within the microwave oven.

\subsection{Bond mechanism and bond failure}

Bond at the plain steel bar and mortar interface is a combination of chemical adhesion and mechanical friction. Chemical adhesion occurs between the cement paste and the steel bars. The mechanical friction occurs due to shrinkage of the mortar matrix around the steel bar, which causes radial compressive stress at the interface [28]. The radial compression and the coefficient of friction provide the friction component of bond strength.

All pull out specimens failed due to pull out of the bars without any splitting or cracking of the matrix, which indicates that their maximum bond strength was achieved. Figure 3 shows a typical sample after the pull out test.

Figure $4 \mathrm{a}, \mathrm{b}$ show the bond stress-slip curves for specimens of repair Material 1 (Series 1, Table 1). The slip values include the elongation of the un-bonded length of the reinforcement in the pull-out specimens (Fig. 1). The elongation was below $10 \%$ of the slip at the maximum pull-out load of specimens. Both

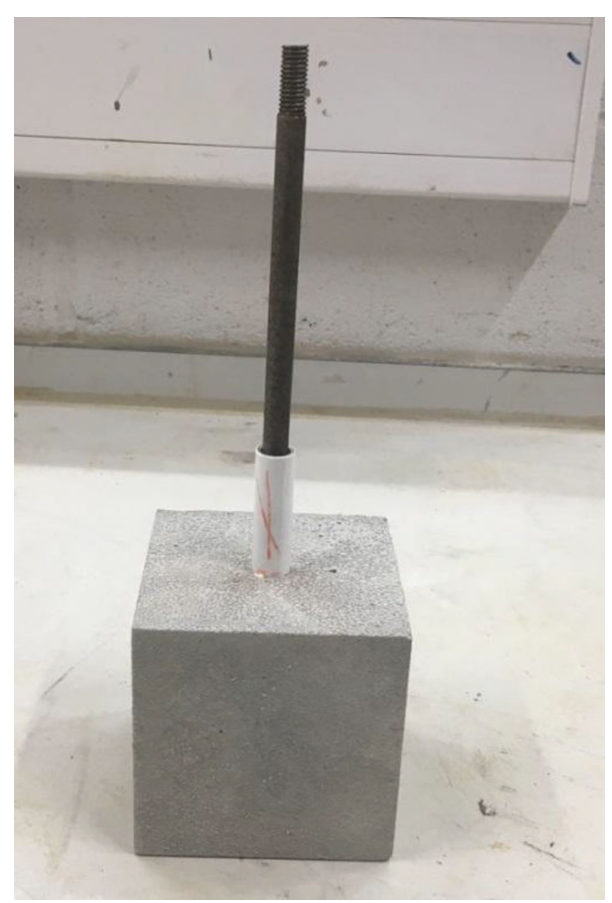

Fig. 3 A typical image of the specimen after the pull out test 
Fig. 4 Bond stress-slip curves of a normally cured; b microwave cured specimens of Material 1 (Series 1)

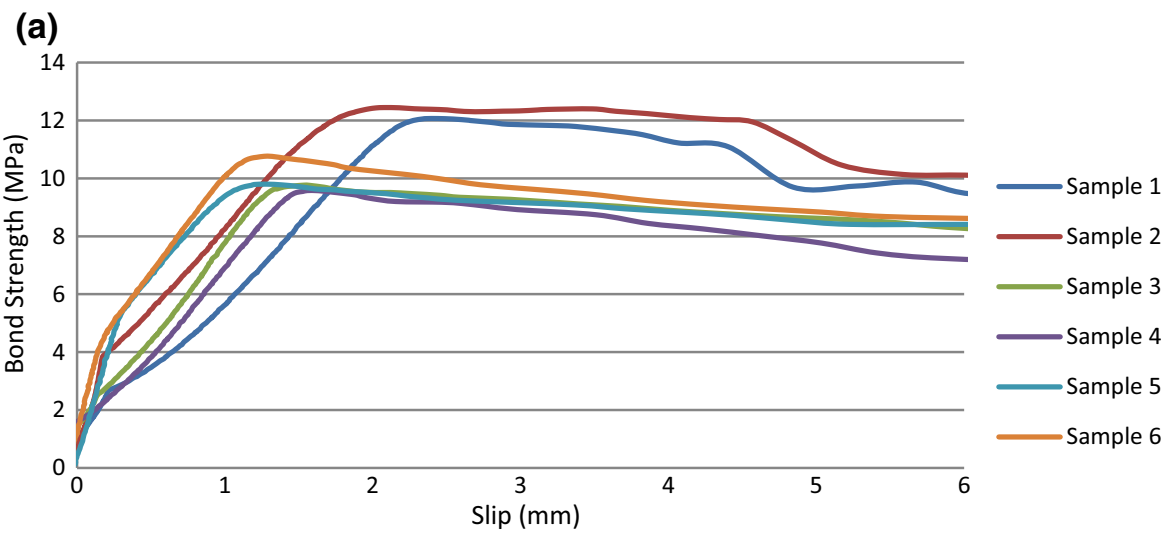

(b)

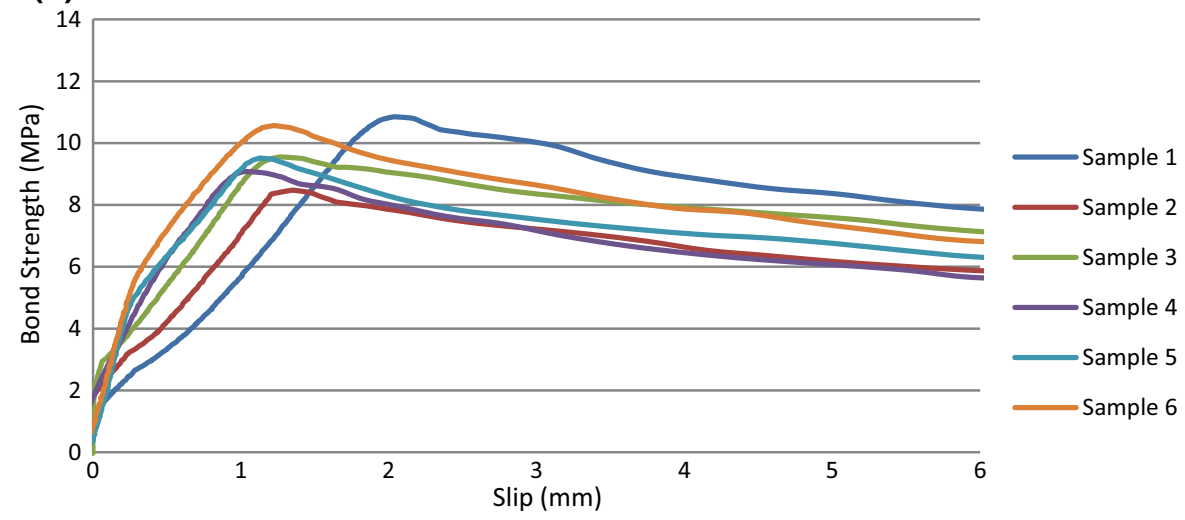

normally and microwave cured specimens show a similar rate of slip. Most test results in Fig. 4a show that after the peak load, bond stress starts decreasing gradually as slip increases. Tests reported in literature on normally cured pull-out specimens of plain rebar in concrete show that the slip increases with applied load until it reaches the maximum stress and then the bond stress drops and continues to decrease gradually as slip increases [29]. In the case of microwave curing (Fig. 4b), the bond stress starts decreasing immediately after the maximum stress in all samples, without an extended plateau on the bond-slip curve which is observed for two of the normally cured specimens in Fig. 4a. The bond after the peak bond stress is mainly maintained by mechanical friction for both curing methods.

\subsection{Effect of microwave curing on bond strength}

The bond specimens for series 1, 2 and 3 were cured at microwave powers of 132, 92 and $60 \mathrm{~W}$, respectively (Table 1). The following sections provide pull-out results separately for series 1 and in combination for series 2 and 3. Each bond strength value given in the paper is the average of 6 pull-out specimens.

\subsubsection{Bond strength of microwave cured samples at 132 Watts}

The average peak microwave curing temperature of the six bond specimens of repair Materials 1, 2, 3 and 4 were $43.1,41.5,41.8$ and $41.6{ }^{\circ} \mathrm{C}$, respectively (Table 2). These were achieved after curing at microwave power of $132 \mathrm{Watts}$ for $20 \mathrm{~min}$ (Materials 2 and 3, Table 1) or $30 \mathrm{~min}$ (Materials 1 and 4, Table 1). Figure 5 and the data in Table 2 show that microwave curing significantly affects the mortar/ steel interface bond strength at 42 days age. Figure 5 shows that from the four repair materials of Series 1, Material 2 and 3 experienced a significant reduction in bond strength with microwave curing. The normally cured Material 3 shows an average bond strength of 6.95 $\mathrm{MPa}$ which reduced to $4.16 \mathrm{MPa}$ due to microwave curing, resulting in a significant loss of $40 \%$. The 


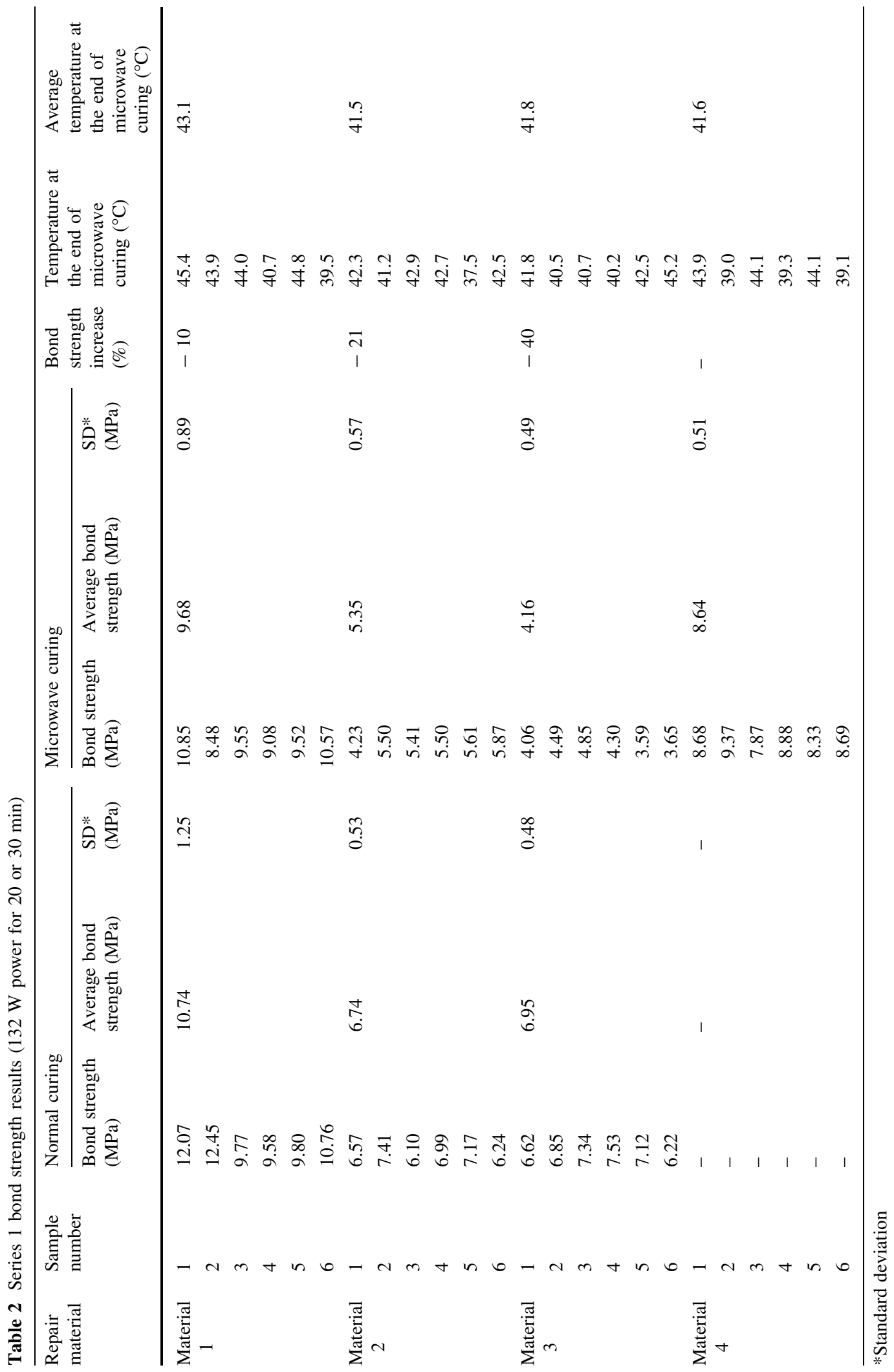


Fig. 5 Comparison graphs of average bond strength (Series 1 microwave power $132 \mathrm{~W}$ for 20 or $30 \mathrm{~min}$ ). *The bond strength for normally cured Material 4 is extrapolated from Fig. 9

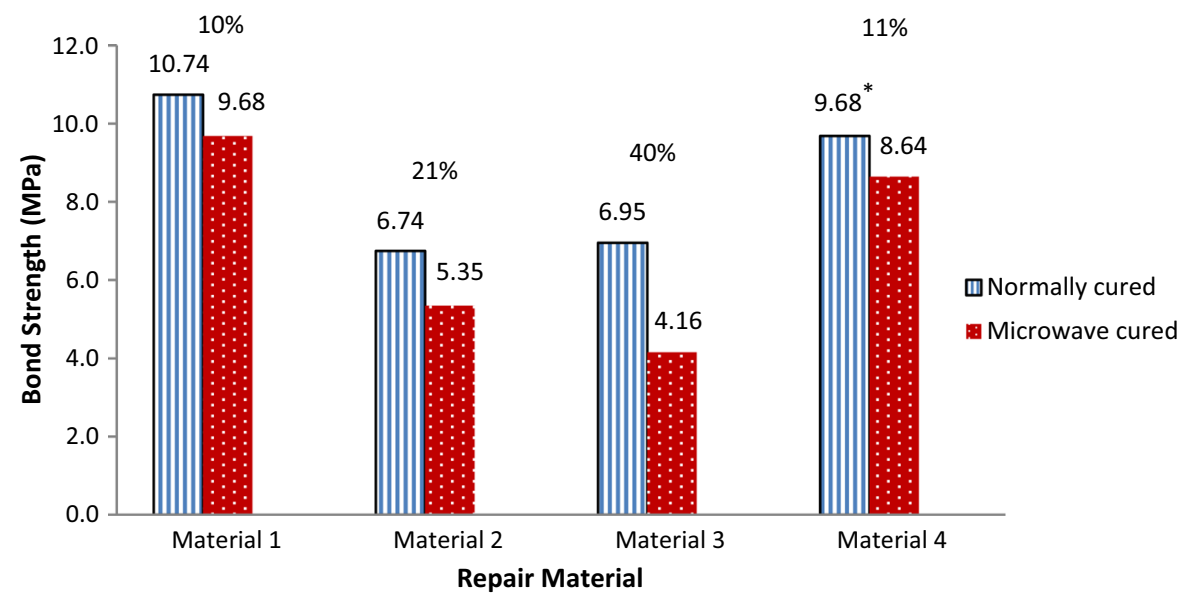

corresponding bond loss was less for Material 2, reducing from $6.74 \mathrm{MPa}$ for normally cured specimens to $5.35 \mathrm{MPa}$ for microwave cured specimens, showing a loss of $21 \%$. Repair Material 1 shows a moderate reduction of $10 \%$ under microwave curing. The bond strength of steel in the normally cured Material 4 was extrapolated from the relationship between bond and compressive strength in Fig. 9 which is discussed in Sect. 3.7. It gives $11 \%$ lower bond with microwave curing.

The results show that microwave curing reduces the bond strength of plain steel reinforcement. The likely factors for this are discussed in the forthcoming sections.

Fig. 6 Comparison graphs of average bond strength of Material 3 for Series 1, 2 and 3 (microwave power $132 \mathrm{~W}$ for $20 \mathrm{~min}, 92 \mathrm{~W}$ for $30 \mathrm{~min}$ and $60 \mathrm{~W}$ for $44 \mathrm{~min}$ )

\subsubsection{Bond strength of microwave cured samples at 92 and 60 Watts}

Figure 5 shows that the maximum reduction in bond strength with microwave curing occurred with repair Material 3 cured for $20 \mathrm{~min}$ to about $40{ }^{\circ} \mathrm{C}$ at $132 \mathrm{~W}$. In order to investigate the effect of lower microwave heating rates on bond strength, series 2 and 3 bond tests were performed on Material 3 at reduced microwave power of $92 \mathrm{~W}$ and $60 \mathrm{~W}$ over a longer period of 30 and $44 \mathrm{~min}$ respectively to provide a temperature of $40-45{ }^{\circ} \mathrm{C}$ (Table 1 ). The results in Fig. 6 show that microwave curing at 132, 92 and $60 \mathrm{~W}$ similarly affected the interfacial bond strength at 42 days age. Material 3 experienced a similar decrease in bond strength of 40,42 and $36 \%$ at the three curing powers of 132,92 and $60 \mathrm{~W}$ respectively,

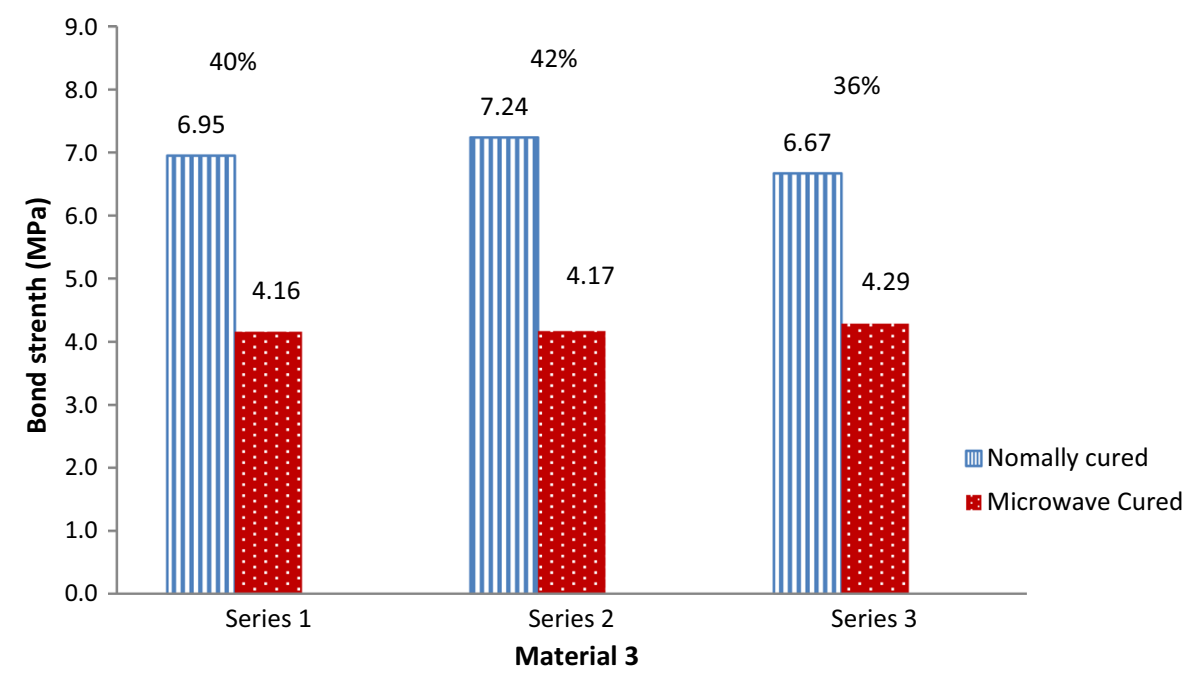


relative to the control specimens. It shows that a lower rate of heating at lower microwave power did not reduce the loss of bond strength relative to normal curing.

Reduction in bond strength reported in this paper concurred with the reduction of bond strength of reinforced concrete due to autoclaving [4] or due to conventional curing at higher ambient temperatures [30]. The reduction of later age bond strength is due to the higher early age curing temperature achieved by microwave curing which accelerates the hydration process. This results in higher early age bond strength, however, the later age bond strength is reduced due to the formation of hydration products of poorer physical structure [4].

In practice, however, the bond strength does not only depend on the properties of concrete but also on many other factors such as the geometry of the reinforcement, thickness of cover and confinement of reinforcement [22]. The reduction of bond strength observed on the plain steel bars with microwave curing may be less significant with deformed reinforcing bars which are normally used in modern concrete construction.

\subsection{Effect of microwave curing on compressive strength}

Figure 7 shows the compressive strength of the four repair materials at 42 days age. It is clear that early age microwave curing ( $132 \mathrm{~W}$ for 20 or $30 \mathrm{~min}$ ) has reduced the 42 days compressive strength for all repair materials.
A comparison of Figs. 5 and 7 shows that the percentages of compressive strength and bond strength reduction with microwave curing are similar for each repair material. Reduction in long term compressive strength due to microwave curing is previously reported by other researchers $[10,31,32]$. It is due to the effect of the short period of high temperature exposure at early age on long-term strength development. A similar reduction of compressive strength also occurs due to conventional heat curing [4, 33-35]. The effect of curing temperature on early and later age strength also depends on the type of cementitious repair materials $[33,36]$. For example, cement type I cured at $40{ }^{\circ} \mathrm{C}$ showed a reduction in its 28 days strength whereas Cem II shows an increase [33]. Both cements showed a reduction in the 28 days strength when cured at $85{ }^{\circ} \mathrm{C}$ [33]. Similar differences are likely in repair mortars which use different types of cements and additives.

\subsection{Effect of microwave curing on shrinkage}

Cement based repair materials exhibit significant shrinkage during service life. The reduction is due to loss of free water in the form of vapour and it depends on the mix proportions, cement replacement materials and admixtures used in the proprietary repair formulations. Shrinkage is a detrimental property of repair materials and a major cause of patch repair failure in service life often due to bond failure at the repair interface [16]. Manufactures often use shrinkage reducing admixtures or expansive cement as shrinkage compensators in repair materials.
Fig. 7 Compressive strength of repair materials at 42 days age (microwave power $132 \mathrm{~W}$ for 20 or $30 \mathrm{~min}$ )

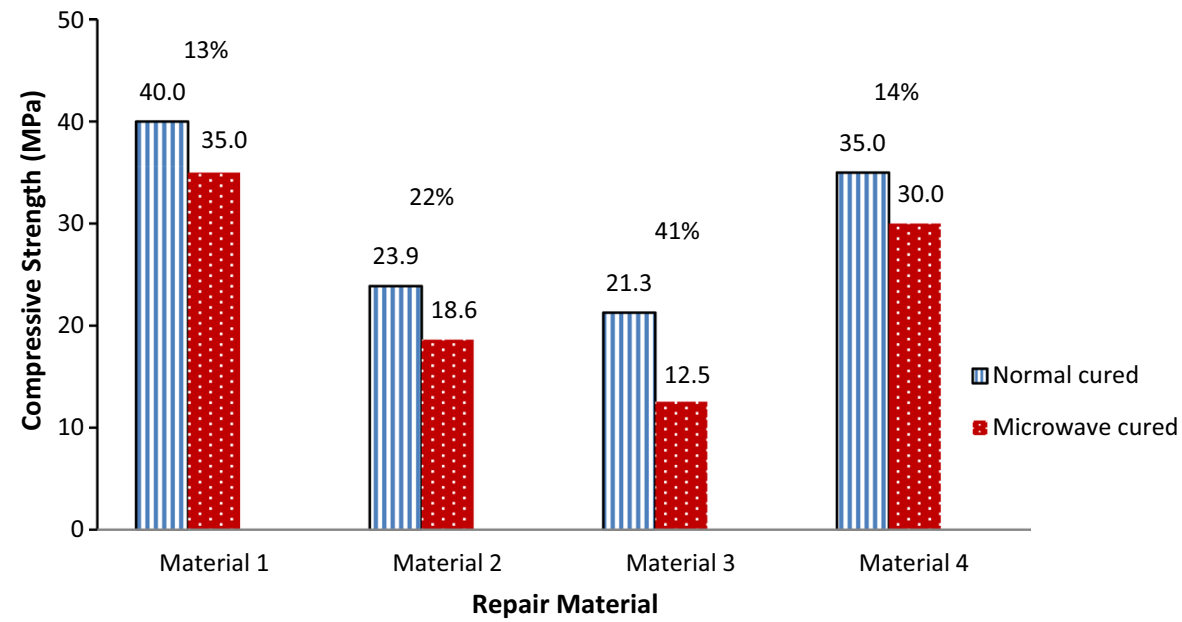


Fig. 8 Drying shrinkage of normally and microwave cured repair materials as a function of time

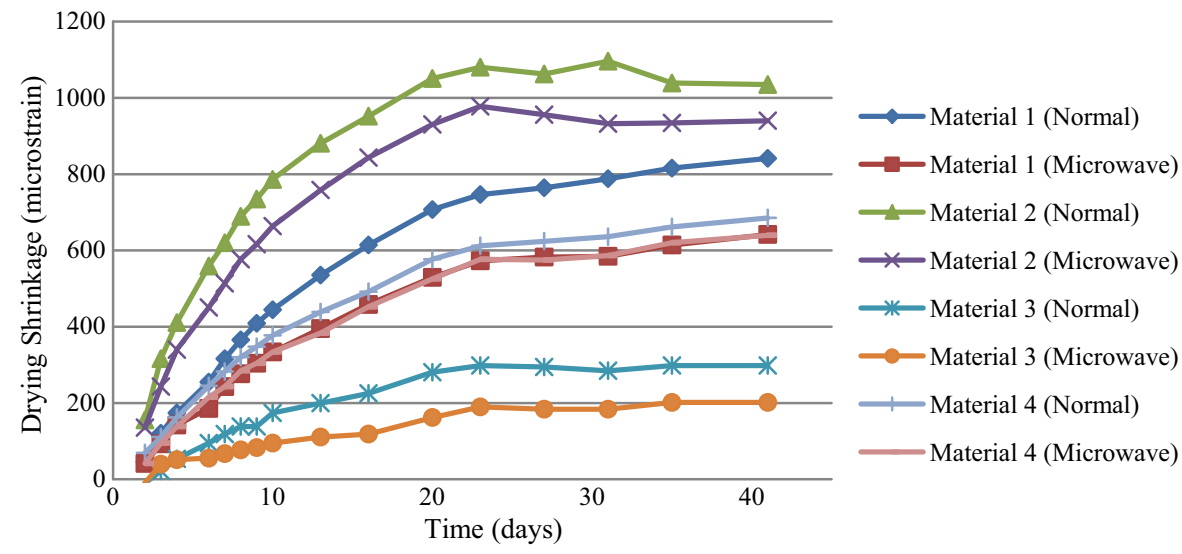

Table 3 Shrinkage of normally and microwave cured specimens at 42 days age

\begin{tabular}{lclr}
\hline Repair material & \multicolumn{2}{l}{ Micro strain $(\mu \mathrm{m})$} & Difference $(\%)$ \\
\cline { 2 - 3 } & Normal & Microwave & \\
\hline Material 1 & 841 & 642 & 24 \\
Material 2 & 1035 & 940 & 9 \\
Material 3 & 298 & 201 & 32 \\
Material 4 & 685 & 640 & 7 \\
\hline
\end{tabular}

Figure 8 and the corresponding data in Table 3 present the drying shrinkage results of microwave and normally cured repair materials. The results are the average of 4 readings for each repair material taken from 2 opposite faces of 2 prisms. The results show that microwave curing reduces the drying shrinkage of all four repair materials. This reduction ranges from $7 \%$ (Material 4) to 32\% (Material 3). Material 2 exhibits the maximum drying shrinkage of 1035 microstrain at 42 days age under normal curing which reduces to 940 microstrain under microwave curing (Table 3). Material 3 exhibits the minimum drying shrinkage of 298 microstrain which reduces to 201 microstrain by microwave curing, resulting in $32 \%$ reduction. This reduction is due to the effect of microwave heating at early age which accelerates hydration and also leads to moisture loss by evaporation [37]. Reduction in shrinkage has also been reported under curing with conventional heating [38, 39].

A comparison of the bond strength and shrinkage of materials 2 and 3 shows the impact of shrinkage on bond strength. For example the 42 days shrinkage for the normally cured repair material 2 is 1035 microstrain compared with 298 microstrain for material 3 (Table 3). Materials 2 and 3 represent the highest and lowest shrinkage curves respectively in Fig. 8 for both normally and microwave cured specimens. The corresponding bond strengths of normally cured Materials 2 and 3 are quite similar at 6.74 and $6.95 \mathrm{MPa}$ respectively. This indicates that shrinkage itself has a modest effect on the bond strength. Other factors such as elastic modulus and density of the matrix also have an impact on the radial stresses induced on the embedded steel. The compressive strengths and, therefore, Elastic modulii [4] of Materials 2 and 3 (normally cured) are similar (23.9 and $21.3 \mathrm{MPa}$ respectively, Fig. 7). The densities of the two materials are also similar.

\subsection{The effect of microwave curing on porosity and pore structure}

The interfacial transition zone (ITZ) between the concrete matrix and steel reinforcement plays an important role in the bond strength of the steel. Heat curing of concrete increases the porosity in the ITZ, which may reduce the bond strength of reinforcement bars. The aim of this investigation is to determine if microwave curing of repair affects reinforcement bond due to the effect of heat curing alone or if microwave exposure has an additional detrimental effect.

Temperatures at the steel surface and in the mortar matrix have been monitored by locating thermocouples at different depths and at the steel surface in 
Table 4 Effect of microwave curing on large and small pores

\begin{tabular}{lllllll}
\hline Material & Location & Curing regime & $\begin{array}{l}\text { Cumulative } \\
\text { intruded volume } \\
\left(\mathrm{mm}^{3} / \mathrm{g}\right)\end{array}$ & $\begin{array}{l}\text { Effective } \\
\text { porosity }(\%)\end{array}$ & $\begin{array}{l}\text { Large pores } \\
(>50 \mathrm{~nm})\left(\mathrm{mm}^{3} / \mathrm{g}\right)\end{array}$ & $\begin{array}{l}\text { Small pores } \\
\left(<50 \mathrm{~nm}^{2}\left(\mathrm{~mm}^{3} / \mathrm{g}\right)\right.\end{array}$ \\
\hline Material 1 & \multirow{2}{*}{ Middle (Bulk matrix) } & Normal & 53.96 & 10.37 & 40.91 & 13.05 \\
Material 2 & \multirow{2}{*}{ Middle (Bulk matrix) } & Normal & 185.48 & 11.98 & 51.87 & 10.39 \\
& & Microwave & 191.71 & 27.92 & 124.31 & 61.17 \\
Material 3 & \multirow{2}{*}{ Middle (Bulk matrix) } & Normal & 184.28 & 27.95 & 145.65 & 46.06 \\
& & Microwave & 226.31 & 28.49 & 148.00 & 36.28 \\
Material 4 & \multirow{2}{*}{ Middle (Bulk matrix) } & Normal & 69.44 & 33.74 & 184.30 & 42.01 \\
Material 2 & \multirow{2}{*}{ Surface (ITZ) } & Microwave & 69.38 & 13.44 & 50.63 & 18.81 \\
& & Normal & 192.73 & 13.88 & 52.30 & 17.08 \\
Material 3 & \multirow{2}{*}{ Surface (ITZ) } & Microwave & 211.13 & 28.42 & 136.98 & 55.75 \\
& & Normal & 183.45 & 31.16 & 164.50 & 46.63 \\
& & Microwave & 221.41 & 27.85 & 141.83 & 41.62 \\
\end{tabular}

microwave cured specimens. Some of the data have been published [40], other are due to be published by the authors. In addition temperature of reinforcement bars protruding from concrete cubes have been monitored during microwave exposure [5]. The results show that the temperatures at the steel surface are the same as the surrounding matrix without any differential created by the steel.

Table 4 shows the effect of microwave curing on the porosity and pore structure of repair materials 2 and 3 in the bond specimens (Fig. 1). MIP test samples were taken from the bond specimens (Fig. 1) at locations representing the bulk material of the cube and the ITZ at the embedded steel surface (denoted as "surface" in Table 4). The bulk material sample was taken close to the middle of the cube but clear from the steel rebar. The ITZ sample was taken at the steel surface. The macro- size interface samples of mortar were taken from the steel surface as described in Sect. 2.3.3. They represent a larger scale of ITZ specimen than the micro-scale samples used for ITZ investigations by other researchers [41].

\subsubsection{The effect of microwave curing on porosity}

Bulk porosity: data presented in Table 4 show that microwave curing has increased the effective porosity of the bulk material, relative to normal curing $\left(20^{\circ} \mathrm{C}\right.$, $60 \% \mathrm{RH})$, for all four repair materials. For example, the effective porosity at the middle of Material 1 increased from 10.37 to $11.98 \%$ under microwave curing. The increase for Material 3 was from 28.49 to $33.74 \%$. The corresponding increase in effective porosity due to microwave curing is very small for Materials $2(27.92-27.95 \%)$ and Material 4 (13.44-13.88\%). The results of Material 4, which is CEM II mortar, are similar to the results from Kong et al. [42] who reported an effective porosity of just below $15 \%$ for a cement mortar under normal curing which increased to just above $15 \%$ under microwave curing.

The increase in porosity under microwave curing is due to the microwave heating applied at early age, similar to the increase in porosity due to conventional heating reported by the other researchers [34, 43-45]. For example, Kjellsen et al. [45] showed an increase in porosity from 10.93 to $15.11 \%$ for plain cement paste cured in water at 20 and $50{ }^{\circ} \mathrm{C}$ respectively, by using backscattered electron image analysis.

ITZ porosity: results presented for Materials 2 and 3 in Table 4 show that the porosity in the ITZ is greater than the bulk porosity for both materials under microwave curing. The ITZ porosity of Material 2 increases from $27.95 \%$ (bulk porosity) to $31.16 \%$. The corresponding values for Material 3 are 33.74 and $35.05 \%$. The differences in ITZ porosity relative to the bulk values under normal curing are insignificant. For example the bulk and ITZ porosities of normally cured 
Material 2 are 27.92 and $28.42 \%$. The corresponding values for Material 3 are 28.49 and $27.85 \%$, both materials showing less than $2 \%$ variation in their bulk and ITZ porosities. These results indicate that the increase in ITZ porosity is greater under microwave curing compared with normal curing. This reduces the bond strength of reinforcement under microwave curing relative to normal curing.

Increased porosity in the ITZ has been previously reported, for example, by Horne et al. [41], at both the steel and aggregate interface with cement paste. However, this was a microscopic investigation of porosity on ITZ samples of micro thickness whereas the present investigation used MIP analysis of macro size samples which represent a greater mean distance from the steel interface compared to the specimens of Horne et al. [41]. The results of Horne et al. [41] indicate an exponential increase in porosity of the ITZ at the steel surface under ambient curing temperature $20{ }^{\circ} \mathrm{C}$.

\subsubsection{Effect of microwave curing on the volume of large and small pores}

Results presented in Table 4 show that microwave curing provides a greater volume of pores larger than $50 \mathrm{~nm}$ for all repair materials compared with normal curing. For example, the cumulative intruded volume of pores larger than $50 \mathrm{~nm}$ for normally cured repair Material 1 is $40.91 \mathrm{~mm}^{3} / \mathrm{g}$ compared with $51.87 \mathrm{~mm}^{3} /$ $\mathrm{g}$ under early age microwave curing. The trend is similar for the other repair materials for both the bulk and interface samples. However, the difference for Material 4 (CEM II) is quite small, increasing from 50.63 to $52.30 \mathrm{~mm}^{3} / \mathrm{g}$.

However, microwave curing provides a lower volume of pores smaller than $50 \mathrm{~nm}$ compared with normal curing with the exception of Material 3. For example, the pore volume for Material 2 (bulk) decreases from 61.17 to $46.06 \mathrm{~mm}^{3} / \mathrm{g}$ under microwave curing. Again, the difference for Material 4, CEM II, is quite small.

In general larger pore sizes $(>50 \mathrm{~nm})$, which refer to capillary pores, are more influential in determining the strength and permeability characteristics and small pores $(<50 \mathrm{~nm})$ play an important role in drying shrinkage and creep properties [46]. Therefore, the reduction of compressive strength of the matrix and bond strength of reinforcement, with early age microwave curing, can be attributed to the increase in the volume of larger pores. On the other hand, the reduction of small pores $(<50 \mathrm{~nm})$ under microwave curing is a reason for providing lower shrinkage reported in Sect. 3.5.

\subsection{Interrelationships between properties}

\subsubsection{Relationship between compressive and bond strength}

Figure 9 shows the relationship between compressive and bond strength for normally and microwave cured specimens at 42 days age. There is a strong correlation between the bond strength of the $10 \mathrm{~mm}$ diameter plain steel bar and compressive strength for all repair materials, both under microwave and normal curing. Material 1 (normally cured) with a maximum bond strength of $10.74 \mathrm{MPa}$ provides the highest compressive strength of $40 \mathrm{MPa}$ while Material 3 (microwave cured) shows both the lowest bond strength (4.16 MPa) and compressive strength of 12.5 MPa.

The relationship between bond strength and compressive strength of concrete is more complex with deformed reinforcement bars which are normally used in modern concrete. In this case, the strength of concrete provides additional bond through mechanical interlock of deformed bars [47] whereas bond strength of plain steel bars is composed of adhesive stress and friction [17]. A non-linear relationship of bond and compressive strength is often used, with the fib code of practice [22] relating bond to the square root of strength. A regression analysis of the data in Fig. 9 gives a similar non-linear equation of the form:

$f_{\mathrm{b}}=0.55 f_{\mathrm{c}}^{0.81}$

where $f_{\mathrm{b}}$ is the bond strength (MPa) and $f_{\mathrm{c}}$ is the compressive strength of the matrix (MPa). The coefficient of correlation is 0.98 which is similar to the strong correlation of the linear relationship in Fig. 9. A wider range of data may have provided a distinction between the two relationships. The power coefficient of 0.81 in Eq. 4 is greater than the values of 0.5 and 0.67 given in literature [22] possibly because it pertains to the data on plain steel bars embedded in proprietary repair mortars. 
Fig. 9 Bond strength versus compressive strength for normally and microwave cured repair materials

Fig. 10 Bond strength versus total porosity for normally and microwave cured repair materials
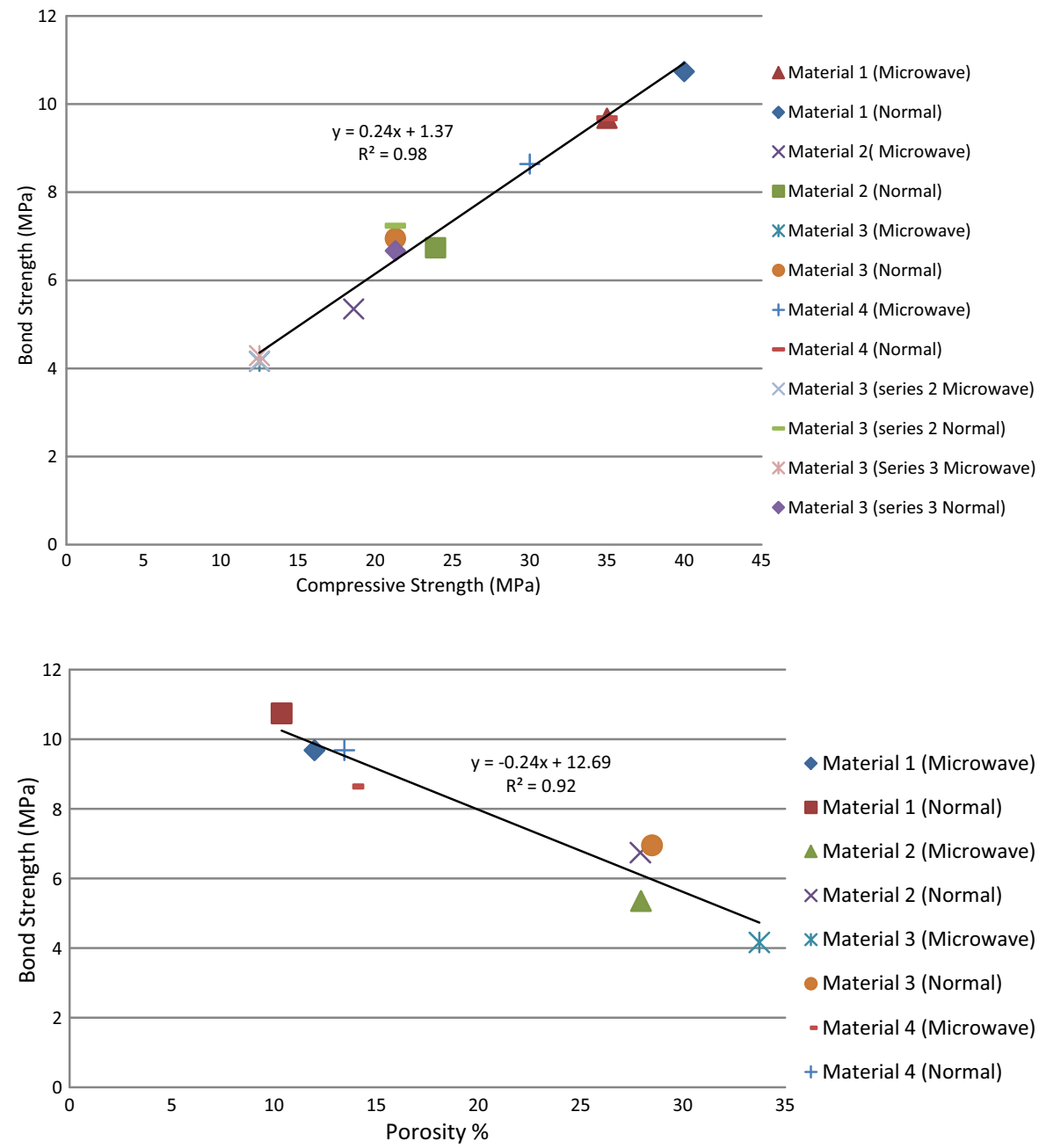

\subsubsection{Relationship between bond strength and porosity}

Figure 10 shows the relationship between bond strength and effective porosity for both normally and microwave cured specimens at 42 days age. The bond strength decreases as porosity increases. For example, normally cured repair Material 1 shows the highest bond strength of $10.74 \mathrm{MPa}$ and the lowest porosity of $10.37 \%$, while microwave cured repair Material 3 shows the lowest bond strength (4.16 MPa) and the highest total porosity (33.74\%).

A non-linear equation between porosity and bond strength is also provided by the regression analysis of the data in Fig. 10, which gives

$f_{\mathrm{b}}=13.81 V_{\mathrm{s}}^{2.58}$ where $f_{\mathrm{b}}$ is the bond strength; $V_{\mathrm{s}}$ is volume of solid matrix $(1-p)$, with a coefficient of correlation of 0.89 .

The strong relationship between bond and compressive strength (Fig. 9 and Eq. 4) and between bond and porosity (Fig. 10 and Eq. 5) implies a similar relationship between compressive strength and porosity, which conforms to existing knowledge on porosity-strength relationship of concrete [4].

\section{Conclusions}

The conclusions apply to cementitious repair mortars exposed to microwave curing after $30 \mathrm{~min}$ of commencing mixing of the repair mortar. Maximum curing temperatures of $41.5-43.1{ }^{\circ} \mathrm{C}$ were achieved 
over a period of 30-44 min. Results presented in the paper show that bond strength of plain steel reinforcement is similarly related to the physical properties (porosity, strength, shrinkage) of both normally and microwave cured mortars. Specific conclusions from the results are as follows:

- Microwave curing reduces the bond strength between repair mortars and plain steel reinforcement by $10-40 \%$. It also reduces the compressive strength of the mortar matrix to a similar degree. This is accompanied by an increase in the volume of capillary pores $(>50 \mathrm{~nm})$ in the matrix. The reduction is greater with low density repair mortars.

- Microwave curing increases the porosity of repair mortars at the interface (ITZ) of the steel reinforcement relative to the porosity of the bulk matrix. The temperature at the steel surface matches the surrounding matrix without any differential caused by the steel surface.

- Microwave curing also increases the porosity of the bulk matrix relative to normal curing under ambient conditions.

- Microwave curing reduces both the drying shrinkage and the volume of small (gel) pores $(<50 \mathrm{~nm})$ of repair mortars.

- The bond strength of steel reinforcement has a unique relationship with the matrix compressive strength and porosity under both normal and microwave curing. It increases both with an increase in the compressive strength and decrease in the porosity of the matrix. Therefore, bondcompressive strength relationships used in the design of reinforced concrete structures will be valid for microwave cured elements.

- Relationships between bond strength $\mathrm{f}_{\mathrm{b}}$, compressive strength $f_{c}$ and porosity $p$ derived in the paper are of the form:

$$
\begin{aligned}
& f_{\mathrm{b}}=0.55 f_{\mathrm{c}}^{0.81} \\
& f_{\mathrm{b}}=13.81 V_{\mathrm{s}}^{2.58} \\
& \text { where } V_{\mathrm{s}}=(1-p) .
\end{aligned}
$$

Acknowledgements The authors gratefully acknowledge the European Commission 7th Framework Programme for financing this research for the MCure project (Grant no:
605664) which has developed a prototype for microwave curing of concrete repair.

\section{Compliance with ethical standards}

Conflict of interest The authors declare that they have no conflict of interest.

Open Access This article is distributed under the terms of the Creative Commons Attribution 4.0 International License (http:// creativecommons.org/licenses/by/4.0/), which permits unrestricted use, distribution, and reproduction in any medium, provided you give appropriate credit to the original author(s) and the source, provide a link to the Creative Commons license, and indicate if changes were made.

\section{References}

1. Matthews S (2007) CONREPNET: performance-based approach to the remediation of reinforced concrete structures: achieving durable repaired concrete structures. J Build Apprais 3(1):6-20

2. Tilly G, Jacobs J (2007) Concrete repairs: observations on performance in service and current practice. IHS BRE Press, Watford

3. ACI Committe 306 (2010) Guide to cold weather concreting (306R-10). American Concrete Institute, Indianapolis

4. Neville AM (2011) Properties of concrete. Pearson Education Limited, Essex

5. Mangat PS, Grigoriadis K, Abubakri S (2016) Microwave curing parameters of in situ concrete repairs. Constr Build Mater 112:856-866

6. Makul N, Rattanadecho P, Pichaicherd A (2017) Accelerated microwave curing of concrete: a design and performance related experiments. Cement and Concrete Composite 83:415-426

7. Buttress A, Jones A, Kingman S (2015) Microwave processing of cement and concrete materials-Towards an industrial reality? Cem Concr Res 68:112-123

8. Xuequan Wu, Jianbgo Dong, Mingshu Tang (1987) Microwave curing technique in concrete manufacture. Cem Concr Res 17(2):205-210

9. Leung CKY, Pheeraphan T (1995) Very high early strength of microwave cured concrete. Cem Concr Res 25(1):136-146

10. Sohn D, Johnson DL (1999) Microwave curing effects on the 28-day strength of cementitious materials. Cem Concr Res 29(2):241-247

11. Makul N, Agrawal DK (2011) Influences of microwaveaccelerated curing procedures on the microstructure and strength characteristics of type 1 Portland cement paste. J Ceram Process Res 12(4):376-381

12. Prommas R, Rungsakthaweekul T (2014) Effect of microwave curing conditions on high strength concrete properties. In: Proceedings of the 11th Eco-Energy and Materials Science and Engineering Symposium-Energy Procedia

13. Mangat P, Grigoriadis K, Abubakri S, Javaid A, Zhao C (2016) Microwave system for in situ curing of concrete 
repair. In: 6th International conference in concrete repair, Thessaloniki

14. Morozov AO, Morozov OA, Kalimullin DZ, Prokopenko AV, Trebukh VP (2016) Research and development of installation for microwave heating of concrete before pouring into molds. In: Actual problems of electron devices engineering (APEDE)

15. Rattanadecho Phadungsak, Makul Natt, Pichaicherd Aumpol, Chanamai Porncharoen, Rungroungdouyboon Bunyong (2016) A novel rapid microwave-thermal process for accelerated curing of concrete: prototype design, optimal process and experimental investigations. Constr Build Mater 123:768-784

16. Grigoriadis K, Mangat P, Abubakri S (2017) Bond between microwave cured repair and concrete substrate. Mater Struct 50(125): $1-14$

17. Xing G, Zhou C, Wu T, Liu B (2015) Experimental study on bond behavior between plain reinforcing bars and concrete. Adv Mater Sci Eng 2015:604280. http://dx.doi.org/10.1155/ 2015/604280

18. Cairns J, Jones K (1995) The splitting forces generated by bond. Mag Concr Res 47(171):153-165

19. Plizzari GA, Deldossi MA, Massimo S (1998) Transverse reinforcement effects on anchored deformed bars. Mag Concr Res 50(2):161-177

20. Metelli Giovanni, Plizzari Giovanni A (2014) Influence of the relative rib area on bond behaviour. Mag Concr Res 66(6):277-294

21. Cairns J, Abdullah R (1995) An evaluation of bond pullout tests and their relevance to structural performance. Struct Eng 73(11):179-185

22. Fib (2010) Fib model code for concrete structures 2010. Ernst \& Sohn, Berlin, October 2013

23. BS EN 12390-3:2009 (2009) Testing hardened concrete. Compressive strength of test specimens. British Standard Institute, London

24. BS EN 197-1 (2011) Cement-Part 1: composition, specification and conformity criteria for common cements. British Standard Institute, London

25. ASTM F1317-98 Standard Test Method for Calibration of Microwave Ovens, ASTM, USA, Reapproved 2012

26. BS EN 60705 (2012) Household microwave ovens. Methods for measuring performance. British Standard Institute, London

27. "BS EN 10080: Steel for the reinforcement of concrete. Weldable reinforcing steel-General. BSI, London," 2005

28. Ferguson PM (1966) Bond stress: the state of the art. ACI 63(11):1161-1190

29. Gambarova PG, Rosati GP, Zasso B (1989) Steel-to-concrete bond after concrete splitting: test results. Mater Struct 22(1):35-47

30. Paul BK, Saha GC, Saha KK, Rashid MH (2013) Effect of casting temperature on bond stress of reinforced concrete structure. Global J Res Eng 13(2):19-23
31. Leung CKY, Pheeraphan T (1995) Microwave curing of portland cement concrete: experimental results and feasibility for practical applications. Constr Build Mater 9(2):67-73

32. Leung CKY, Pheeraphan T (1997) Determination of optimal process for microwave curing of concrete. Cem Concr Res 27(3):463-472

33. Elkhadiri I, Palacios M, Puertas F (2009) Effect of curing temperature on cement hydration. Ceram Silik 53(2):65-75

34. Ballester P, Hidalgo A, Mármol I, Morales J, Sánchez L (2009) Effect of brief heat-curing on microstructure and mechanical properties in fresh cement based mortars. Cem Concr Res 39(7):573-579

35. Lothenbach Barbara, Winnefeld Frank, Alder Corinne, Wieland Erich, Lunk Peter (2007) Effect of temperature on the pore solution, microstructure and hydration products of Portland cement paste. Cem Concr Res 37:483-491

36. Wang P, Liu X (2011) Effect of temperature on the hydration process and strength development in blends of Portland cement and activated coal gangue or fly ash. J Zhejiang Univ Sci A 12(2):162-170

37. Bissonnette Benoît, Pierre Pascale, Pigeon Michel (1999) Influence of key parameters on drying shrinkage of cementitious materials. Cem Concr Res 29(10):1655-1662

38. Hanson JA (1964) Prestress loss as affected by type of curing. J Am Concr Inst 9(2):69-93

39. Bakharev T, Sanjayan JG, Cheng Y-B (1999) Effect of elevated temperature curing on properties of alkali-activated slag concrete. Cem Concr Res 29:1619-1625

40. Mangat PS, Grigoriadis K, Abubakri S (2016) Temperature development in microwave cured repair materials. In: Proceedings of 6th international conference on concrete repair, Thessaloniki

41. Horne AT, Richardson IG, Brydson RMD (2007) Quantitative analysis of the microstructure of interfaces in steel reinforced concrete. Cem Concr Res 37(12):1613-1623

42. Kong Y, Wang P, Liu S, Gao Z (2016) Hydration and microstructure of cement-based materials under microwave curing. Constr Build Mater 114:831-838

43. Khatib JM, Mangat PS (1999) Influence of superplasticizer and curing on porosity and pore structure of cement paste. Cem Concr Res 21:431-437

44. Kjellsen KO, Detwiler RJ, Gjørv OE (1990) Pore structure of plain cement pastes hydrated at different temperatures. Cem Concr Res 20:927-933

45. Kjellsen KO, Detwiler RJ, Gjørv OE (1991) Development of microstructure in plain cement pastes hydrated at different temperatures. Cem Concr Res 21(1):179-189

46. Mehta PK, Monterio PJM (2005) Concrete microstructure, properties, and materials, 3rd edn. McGraw-Hill, New York

47. Chen H-J, Huang C-H, Kao Z-Y (2004) Experimental investigation on steel-concrete bond in lightweight and normal weight concrete. Struct Eng Mech 17(2):141-152 